\title{
PROCESSO GRUPAL: REFLEXÕES DE UMA PRÁTICA COM JOVENS EM SAÚDE MENTAL
}

[Group process: reflections on a practice with youngsters in mental health]

\author{
Cláudia Márcia Vieira Gusmão*
}

RESUMO: Neste trabalho são apresentadas reflexões sobre uma prática realizada com jovens em Saúde Mental. Sintetizam uma parte da pesquisa realizada para Dissertação do Mestrado em Psicologia. Utilizei como referência teórica autores da Psicologia Social, que trabalham com uma concepção dialética de homem e de grupo, principalmente os estudos de Ignácio Martín-Baró e Silvia Lane. Estes autores postulam que o grupo é um processo permeado por contradições que refletem a sociedade onde seus participantes estão inseridos. Procurei também refletir sobre esta prática no contexto das transformações que vêm sendo realizadas com a Reforma Psiquiátrica. Com relação aos aspectos metodológicos, utilizei a pesquisa qualitativa e, como instrumento de coleta de dados, a observação participante. Os dados empíricos foram agrupados e analisados a luz das categorias teóricas assinaladas pelos autores citados. Os resultados da pesquisa sinalizaram para a importância de se refletir sobre as práticas sociais realizadas em distintos contextos sociais, buscando adequá-las à realidade da população, além da necessidade de espaços de interação social abertos ao diálogo e à construção de vínculos afetivos importantes para o fortalecimento da identidade dos jovens. No contexto da saúde mental, considero também importante abordar a interação com outros segmentos sociais, possibilitando a construção de uma prática interdisciplinar que permita a multiplicação de informações, trabalhando sobre os preconceitos, reduzindo-se assim a exclusão social.

\footnotetext{
*Assistente Social da Fundação de Ação Social de Curitiba/PR É presidente da Associação Arnaldo Gilberti - Espaço Paranaense de Saúde Mental. Especialista em Política de atendimento à Criança e ao Adolescente pela UEPG e Mestre em Psicologia da Infância e da Adolescência pela Universidade Federal do Paraná.
}

PALAVRAS CHAVES: Processo grupal; Adolescentes; Prática social; Saúde mental.

\section{INTRODUÇÃO}

"Como poderão as novas gerações aprender a viver juntas no mundo do amanhã?... Muitas respostas a estes desafios podem e devem vir dos próprios jovens, se lhes for dada a oportunidade de se manifestar. O potencial é considerável". JAVIER PERES CUÉLLAR, 2002

No final da década de 80 o campo da saúde pública passou por importantes transformações, caracterizadas por uma ruptura com o modelo essencialmente clínico e biologizante para uma concepção de saúde mais ampla que envolve outros processos sociais.

Essa mudança de paradigmas na saúde coletiva é vista por Ramos (2001, p.15) como:

um processo histórico e social, problematizando a organização das práticas, enfatizando a promoção de saúde a partir da reorganização da vida social e não apenas a partir dos serviços de saúde, articulando, portanto, estratégias mais amplas de construção da cidadania e de transformação da cultura da saúde.

Outras transformações também ocorreram na mesma década no âmbito da saúde mental, configurando-se na Reforma Psiquiátrica Brasileira, que apontou para a construção do paradigma psicossocial e impulsionou 0 delineamento de diferentes práticas neste campo. Surgiram então novas experiências de intervenção para atendimento ao portador de sofrimento psíquico. Dentre estas formas de intervenção, destaca-se a retomada de atividades grupais como possibilidades de trabalhar outras formas de atendimento em saúde mental.

Contudo, permanecem ainda hoje, no âmbito 
da saúde mental, muitas práticas grupais que reproduzem o modelo de atendimento terapêutico tradicional, que legitimam a doença mental e fortalecem a exclusão dos usuários desses serviços. Nestas práticas se vêem claramente uma dicotomia nas propostas de trabalho em grupo ${ }^{1}$, separando-as em atividades clínico-terapêuticas em algumas e em outras privilegiando apenas as oficinas produtivas.

Por se fundamentar nos modelos tradicionais de grupo, essas propostas têm como princípio uma concepção de grupo como um sistema fechado, previamente constituído. Visão que mascara as relações que surgem dentro da prática grupal, como as necessidades e interesses dos sujeitos, as tensões, os conflitos e as relações de poder. A postura idealista presente em algumas práticas grupais não permite a percepção de seu movimento em constante construção e transformação.

Barros et al. (2001) propõem uma outra forma de pensar o trabalho em grupo, compreendendoo como dispositivos que têm condições de habitar um outro regime de enunciação, no qual as atividades clínico-terapêuticas e as oficinas produtivas formem um espaço indissociável de mútuo engendramento, onde a dimensão de cidadania e política estejam presentes.

É dentro desta perspectiva que se deu a opção por refletir sobre uma prática de grupo desenvolvida com jovens em uma instituição de saúde mental. Esta reflexão foi orientada pelos estudos de grupo fundamentados na concepção histórico-cultural, que possibilitou a percepção do movimento e da historicidade do fenômeno estudado. Para isto, utilizei um aporte teórico dentro do materialismo histórico-dialético, que me permitiu ampliar o olhar sobre os jovens e o grupo. Fundamentei-me nas propostas de Martin-Baró (1993) e Lane (1984), que apontam para uma concepção dialética de homem e de grupo humano. Este referencial dialético possibilita uma compreensão da constituição dos sujeitos em diferentes grupos sociais em toda a sua dimensão e potencialidade, permite também conceber o

${ }^{1}$ Estou utilizando grupo (em itálico) para referir ao conceito clássico tradicional, distinguindo-o de uma concepção dialética de grupo que também é visto enquanto um processo grupal. grupo como um sistema aberto, dinâmico, permeado por contradições e conflitos sociais em que os jovens que dele participam determinam e são determinados pelo processo onde estão inseridos.

De acordo com as psicólogas sociais Lane e Freitas (1997, p.296), "a referência do indivíduo dentro de um sistema social dá-se mediatizada pela sua pertinência a um ou mais grupos, que têm importância fundamental na sua vida".

Nos jovens, o convívio grupal permite o desenvolvimento de uma interação pela compreensão das diferenças e pela expressão das singularidades, além de outras determinações na construção da sua identidade.

Considerando que a prática de atendimento na saúde mental foi por muito tempo marcada por enfraquecimentos dos vínculos sociais, desqualificação social dos usuários, pela fragilidade e a dependência em decorrência da ruptura ou diminuição de interações sociais, trazendo como conseqüência a exclusão social. Compreendo que uma prática grupal que leve em conta a constituição dos sujeitos possibilita sua inclusão no meio social, sendo necessária nesse novo contexto que se desenha na saúde mental.

Parto da concepção que as interações que se estabelecem no grupo estão inseridas em um contexto social maior e que as ações e representações dos jovens não podem ser entendidos como idiossincrasias pessoais, mas como resultado de práticas que se produziram historicamente na convivência social. Assim, não devem ser isolados de sua gênese, das regras e funcionamento das várias instituições onde as interações acontecem e dos valores e crenças presentes em relações sociais mantidas entre sujeitos em interação.

Lane (1984, p.78) ao fazer uma revisão dos estudos sobre pequenos grupos na Psicologia Social, considera que o grupo é: "condição necessária para conhecer as determinações sociais que agem sobre o indivíduo, bem como a sua ação como sujeito histórico, partindo do pressuposto que toda ação transformadora da sociedade só pode ocorrer quando os indivíduos se agrupam".

Martin-Baró (1993) conceitua grupo a partir de uma revisão crítica das duas teorias que mais influenciaram os modelos atuais: a teoria psicanalítica, de Sigmund Freud, e a teoria de 
campo, de Kurt Lewin. Com base na crítica a esses modelos teóricos, Martín-Baró (1993, p.206) define grupo como "uma estrutura de vínculos e relações entre pessoas que canalizam em cada circunstância suas necessidades individuais e os interesses coletivos". Para ele, o grupo é uma estrutura social que é compreendida como uma realidade total, um conjunto que não pode ser reduzido à soma de seus constitutivos.

Lane e Martín-Baró compreendem que o grupo se estrutura em função de uma relação dialética com a realidade, onde estão presentes as contradições sociais e diferentes interesses, muitas vezes antagônicos, mas que refletem a sociedade onde o grupo está inserido.

Para Lane (1984, p.81), o significado da existência e da ação grupal só pode ser encontrado dentro de uma perspectiva histórica que considere a sua inserção na sociedade, com suas determinações econômicas, institucionais e ideológicas e por isto o próprio grupo só poderá ser conhecido enquanto um processo histórico, e "neste sentido talvez fosse mais correto falarmos em processo grupal, em vez de grupo".

Heller (2000), ao tratar do homem na vida cotidiana, compreende o grupo enquanto um espaço onde nascem as experiências de transformação individual e social. Para a autora, nossa vida cotidiana é heterogênea, contendo vários aspectos relacionados á vida privada - como o trabalho e o lazer - que são adquiridos e sistematizados socialmente. $\mathrm{O}$ desenvolvimento dessas habilidades ocorre através de diferentes grupos.

No meio social, observa-se a existência de diversos grupos constituídos e estruturados para fins específicos, como forma de organização da sociedade para atender às contradições do seu sistema social. Muitos desses grupos são estruturados e organizados pelos próprios participantes, às vezes com apoio de profissionais e voluntários, entre eles os Alcoólicos Anônimos, Narcóticos Anônimos, sindicatos, associações e movimentos ligados à igreja ou às comunidades.

Martin-Baró (1993) irá afirmar que muitos destes grupos sociais são formados forçosamente, de maneira intencional ou como conseqüência indireta de processos discriminatórios. O que ressalta, nesses grupos, é a prevalência de um tipo de pessoa socialmente estigmatizada, como ocorre em alguns grupos institucionais de deficientes físicos, de negros, de mulheres, entre outros.

\section{METODOLOGIA}

Partindo destes pressupostos teóricos utilizei como referência metodológica à pesquisa qualitativa, com ênfase na observação participante, conforme indicada por Minayo (2000), para perceber a interação grupal num movimento histórico-dialético. A escolha deste tipo de pesquisa foi considerada em virtude da necessidade de maior inserção no contexto organizacional procurando, em um primeiro momento, uma aproximação com a realidade, com os sujeitos envolvidos e com a problemática a ser estudada.

A pesquisa qualitativa possibilitou-me encontrar espaços para entender o cotidiano dos jovens pesquisados, oferecendo também a oportunidade de junto com eles viver o processo de construção de um trabalho conjunto. A aproximação dos jovens, nessa prática grupal, permitiu perceber a interação entre eles e, principalmente, vivenciar situações mais profundas de vínculos que iam se estabelecendo ao longo do processo grupal, dado o clima de confiança e a proximidade entre as pessoas envolvidas.

Sallas et al. (1999), na perspectiva sociológica, argumentam que a pesquisa qualitativa procura o sentido, o conteúdo das manifestações da vida social, própria dos sujeitos que interagem em um universo possível de significações (individuais, sociais e culturais), atribuídas tanto à ação, quanto na relação com os outros. As relações humanas são permeadas pelas dimensões emocionais, racionais, também pelas contradições, coerências e aspirações reveladas nas atividades e concretizadas através dos sujeitos. São estes aspectos que procurei observar no desenvolvimento da pesquisa.

Considerando minha opção pela observação participante, e cumprida as formalidades legais para o desenvolvimento da pesquisa, como a aprovação pelo Comitê de Ética e Pesquisa - de acordo com a resolução 196/96, e após a autorização do profissional responsável pelas atividades com os jovens, elaborei um instrumento de coleta de dados, no qual procurei registrar sistematicamente todas as informações e dados 
que ia observando nos encontros dos jovens.

Realizei também o registro, por meio de filmagens e fotografias, de alguns momentos dos jovens nas atividades. Para garantir o anonimato dos participantes, e transcrever trechos importantes dos diálogos dos mesmos, utilizei as letras iniciais de cada nome. Utilizei a letra $P$, para indicar a intervenção do pesquisador.

Realizando um contato mais próximo com os jovens, pude observar mais atentamente os valores expressos pelos mesmos, o estilo do relacionamento entre eles, a expressão criativa e lúdica nas atividades, evidenciadas por expressões verbais e corporais. Aos poucos, fui conhecendo o "vir-a-ser" desses jovens, surgindo vários aspectos que me ajudaram a delinear mais claramente a pesquisa.

\subsection{SUJEITOS}

Esta pesquisa foi desenvolvida durante os anos de 2002/2003, com um grupo de jovens que estavam em atendimento em saúde mental e participavam de atividades semanais na Associação Arnaldo Gilberti (AAG). Esses jovens foram para lá encaminhados por profissionais da saúde, em sua maioria do Centro Psiquiátrico Metropolitano (CPM). Nesses encontros eram realizadas atividades de biodança, desenho/ xilogravura, noções de informática e confecção de bijuterias, ministradas por profissionais voluntários. Participavam também outros jovens, parentes ou amigos, convidados pelos próprios participantes.

Os encontros aconteciam todas às quintasfeiras, das 14 às 16 horas, onde os jovens participavam de atividades alternadas de confecção de bijuterias, desenho com xilogravura, biodança e noções de informática.

Participaram mais intensamente nove jovens, com idades entre 12 e 28 anos. Eram advindos das classes populares, residentes em bairros de Curitiba e região metropolitana, e em seus relatos expressavam os diferentes motivos que os levaram a participar dos encontros da Associação. Entre estes motivos estavam as dificuldades relacionadas à escola, ao relacionamento familiar, relatos de tratamento por uso de drogas e outros atendimentos psiquiátricos. Todos os participantes eram acompanhados por psicólogos e/ou psiquiatras no Centro Psiquiátrico
Metropolitano e quatro faziam uso de medicamentos.

Nas falas dos jovens e de seus familiares eram enfatizadas as dificuldades de relacionamento, consideradas por alguns como problemas de conduta e rebeldia no âmbito escolar e familiar. Contudo, a concepção retratada por eles contradizia a participação dos mesmos nas atividades, uma vez que não encontrei na interação deles quaisquer dados que comprovassem essas falas. O mesmo se deu com os jovens que tinham uma história de isolamento social. Estes, não só participavam ativamente das atividades, como também tinham atitudes de solidariedade e atenção para com os colegas. Este dado também foi constatado na fala de alguns jovens: quando indagados por que participavam das atividades na AAG, apontavam a interação com os outros e a possibilidade de ter novas amizades, como nesta fala:

R: Por motivo de... melhorar a minha pessoa... Tanto aqui, na escola, na rua... com as pessoas, em todo lugar... e...saber conversar, saber fazer alguma coisa na vida, né?... e... principalmente arranjar amigos, é... enfim. (DC 29/08, p.33).

Em geral, os jovens não relacionavam suas dificuldades com problemas psíquicos, e sim, abordavam-nas como crises que se manifestavam de diferentes formas:

F: Ah! eu começo a ficar irritado, eu já não dormi...parece que o mundo acabou, pois eu não consegui dormir, né? vem a irritação daí eu tenho que conversar com pai, conversar com a mãe... daí não posso... não cumpro os compromissos combinados... acabo ficando em casa... e eu tava em crise assim aí ele me levou lá psicóloga lá no CPM, e me deram uma injeção, né!por que eu tava em crise assim... e daí eu não sei se melhorei... eu fiquei meio bobo assim... meio de...sei lá dá uma esfriada nos ânimos... Era mais... eu não sei... é mais... como vou dizer... um sentido de autopreservação, assim... como se eu quisesse me salvar... é como se eu tivesse morrendo...e falasse assim... pô me salve! Eu preciso de ajuda... daí eu vou lá e eles me dão uma injeção... daí eu melhorei. mas eu não sei... não sei nem como é que é...(DC 31/10, p.64, grifos meus).

Os jovens demonstravam muitas dificuldades em falar de sua situação de saúde mental e do tratamento que faziam. Isso só foi possível após o estabelecimento de vínculos de confiança entre a pesquisadora e os participantes. Relatavam sentir o preconceito e rejeição por parte 
das pessoas em relação aos seus problemas:

F: Acho que senti. até... mais um pouco de rejeição das pessoas... Ah! eu sinto assim um pouco de medo das pessoas... mas...

M: O que te dá medo nas pessoas...?

F: Ah não sei, às vezes no que eu penso... assim... não me compreendem... Não conseguem... como é que é...

V: Te aceitar... (DC 19/09 p.38).

O sentimento deste jovem era compartilhado pelos outros participantes que, de diferentes modos, sinalizavam que não queriam ser identificados como portadores de transtornos mentais. Esse fato foi evidenciado pela dificuldade deles em participar de eventos abertos à comunidade. Definiram assim suas dificuldades:

V: É... eu fico com vergonha

$\mathrm{J}$ : Eu também fico com uma vergonha do caramba... de estar com o grupo......não é o que eu penso... é o que o povo pensa... V: É que você não conhece o "meu colégio" [refere-se aos colegas da turma...]...o pessoal é muito sarrista...

$\mathrm{J}$ : É por que é o seguinte... o povo tem um certo preconceito, né?...

R: Falam que é maluquice, né... (DC 17/10, p.49-50).

As questões do estigma e do preconceito foram sinalizadas durante todo o processo e demonstrado pela dificuldade dos jovens se reconhecerem enquanto fazendo parte da Associação. Alguns jovens não queriam participar e relatavam que não tinham nenhum problema. Havia familiares que faziam questão de frisar que seu filho só estava acompanhando e que não tinha "problema mental". O trabalho na AAG era visto como para portadores de transtorno mental, ou como na expressão deles como para "doentes mentais".

Estes jovens também tinham muitas dificuldades de falar de situações da sua vida, principalmente de aspectos relacionados à sua escolaridade, como nesta observação do pesquisador:

P: Durante as apresentações no grupo um dos jovens pediu para não que eu não perguntasse a escolaridade dele, pois tinha vergonha de falar que estava na $1^{\text {a }}$ série/classe especial. (DC 23/05, p.10).

Comparando os dados levantados com os da pesquisa "Os Jovens de Curitiba: esperanças e desencantos" (Sallas, 1999), observei que esses jovens, como quaisquer outros, tinham vários interesses e expectativas em relação ao futuro.

Entre os interesses apontados, observei a busca pelo acesso aos meios tecnológicos, principalmente com a informática, como necessário à formação profissional.

Dentre as atividades realizadas que mais despertavam o interesse dos jovens, estava a biodança, que foi abordada pelos participantes do seguinte modo:

$\mathrm{J}$ : Eu acho que é uma coisa que relaxa, uma coisa diferente, né? Pois na aula a gente fica o tempo todo sentado em sala de aula, em casa é aquela correria. Então não é dança, é uma coisa que relaxa, eu gosto... (DC, 29/08, p.29).

O interesse pela atividade de biodança surgiu também pela oportunidade dos jovens poderem expressar-se verbalmente, falando de si mesmos e dos seus sentimentos e sendo ouvidos pelos demais participantes.

Em outras ocasiões, os interesses pelas atividades estavam relacionados à possibilidade de realizarem outras coisas as quais não tinham acesso em casa ou na comunidade.

Os jovens também expressavam a necessidade da convivência grupal, da amizade e do companheirismo. Enfatizavam a importância da troca, da partilha verbal e de poder contar com outras pessoas para ouvir e aconselhar:

$\mathrm{J}$ : Eu me senti, uma coisa que tá acontecendo comigo, é que eu tô conseguindo fazer muito mais amigos... no trabalho... M: tá trabalhando?

J: uhum! tô conseguindo fazer... tô trabalhando faz duas semanas... eu sou amigo de quase todo mundo... do mercado... sabe? Já fiz amizade com quase todo mundo... eu me sinto diferente né?... me sinto mais feliz. Ë legal, você ter um monte de amigos assim... isto que achei que mudou bastante... (DC 19/09, p.38).

F: É... mas por exemplo, quando uma pessoa tá com depressão... e alguém vai lá e procura ajudar ela... mas não é imediatamente que ela vai sair da depressão e por isto é preciso paciência... e depois da paciência vem o coleguismo... a amizade... para elas seguirem juntas... para um... futuro melhor... (31/10, p.71).

Abordavam suas expectativas em relação ao futuro quando falavam de seus interesses em continuarem os estudos e da realização do vestibular. Esses interesses e expectativas estavam intrinsecamente relacionados com suas condições sociais. Aqueles que possuíam uma condição sócio- 
econômica mais desfavorável, com baixa escolaridade, tinham mais muitas dificuldades em expressar seus projetos de vida e até mesmo indicar a escolha de uma profissão:

V: No meu curso... Web-designer...eu ainda não sei... parece que tem doze ou treze por vaga...

F: Eu gosto de música, vou fazer na "FAP" pra Licenciatura em música... na Federal coloquei Ciências Sociais...

FR: Meu objetivo era ser aeromoça... mas é muito difícil, né?... C: O que eu mais gosto? Ah...eu gosto de lutar... jogar capoeira.... eu jogava... o que eu gosto mais... a biodança e... o computador... eu nunca mexi com computador na vida... só mexo aqui...tô aprendendo. (DC 21/11, p.77-79).

Os dados demonstram que esses jovens não estavam alheios aos temas da atualidade, conversavam sobre diversos assuntos, sendo enfatizados aqueles que eram mais veiculados pelos meios de comunicação de massa, especificamente pelo rádio e pela televisão. Os assuntos abordados durante as atividades refletiam o contexto sócio-histórico destes sujeitos e tinham forte conteúdo ideológico, fortemente transmitido pelos meios de comunicação. Conforme assinalado por Sallas et al. (1999), a TV é o instrumento de mídia mais presente no cotidiano dos jovens. Os programas da TV apareciam de modo predominante nos diálogos dos jovens durante a realização das atividades:

P: (...) falam dos programas de televisão, entre eles, Os Normais, Big Brother Brasil, Casseta e Planeta, da nova 'novela das oito', filmes novos e assuntos jornalísticos, como o desaparecimento e a morte do jornalista Tim Lopes, de violência urbana, da favela, do futebol e da Copa do Mundo, sobre política, em especial as eleições (...) Sobre os programas de rádio, comentam sobre as músicas da Jovem Pan, da Transamérica, contam piadas que são repassadas pelo rádio e na internet. (DC 20/06, p.17).

Os jovens também abordavam a questão política, cujo tema principal na época da pesquisa era as eleições. No diálogo seguinte é enfatizada a percepção dos jovens acerca dos políticos, de modo geral. Da análise surgiu um aspecto interessante: ao mesmo tempo em que aparentavam demonstrar uma certa consciência crítica da situação política brasileira, também explicitava a idéia de que apenas repetiam o que era veiculado pelos meios de comunicação:

JO: É a gente vai ter que votar de novo... que horror!
J: Agora vocês vão se matar ou se suicidar [falando dos dois candidatos...] Vão votar em se matar ou vão votar em se suicidar.

JO: não vai mudar mesmo... Estão falando que é melhor votar no JS do que votar no Lula... [Jor fala junto: Lula é muito fraco], né...mesmo assim acho que vou votar no Lula... mas estão dizendo que o Lula não vai pagar a dívida do Brasil... J: Deputado é do mesmo jeito, é ladrão do mesmo jeito... eles roubam do mesmo jeito... não tem jeito..... JJor vai falando sem ouvir direito os colegas/Jô... ou retruca ou que ela diz]. J: Claro que não, pois o Brasil não está mais devendo...né por que o seguinte... o Brasil não está mais devendo... o Brasil tá pagando de bobo...por que tanto de dinheiro que o Brasil já pagou... não era prá tá devendo mais... (DC17/10/03, p.52).

Nas conversas eram abordados outros assuntos relacionados ao futebol (Campeonatos, Copa do Mundo), falavam a religião, referiam-se à igreja da qual alguns participavam. Porém, também retratavam os escândalos noticiados pelos meios de comunicação:

V: Em Bispo não dá prá confiar, né... O Bispo XXX não rou.../ pega dinheiro dos pobres, né...?

J: Eu não sou da igreja dele...pode roubar a vontade, não é o meu dinheiro... (DC, 17/10/03, p54).

A amizade era um dos valores mais importantes para os jovens pesquisados. Era um assunto sempre presente nos diálogos. Falando sobre a amizade, faziam reflexões sobre diferentes aspectos do cotidiano. Na questão da amizade, refletiam também sobre a importância do companheirismo:

P: V na outra ponta, disse baixinho que não tinha amigos... Perguntei para ela por que ela achava que não tinha amigos... Ela disse que amizade era uma coisa importante, que amizade verdadeira poucas pessoas tem e às vezes é só de alguém da família tipo a mãe, a irmã. Ela disse que tinha "colegas" e que era diferente de "amigos". Lora discordou de Vanilda e disse que tinha muitos amigos e achava que ela era amiga da Vanilda. Disse que amizade exige confiança e que nós precisamos de amigos... Outros jovens confirmaram a fala de Lora (DC 13/06, p.14).

\section{REFLEXÕES SOBRE O “ESTAR” EM GRUPO: ALGUMAS CONSIDERAÇÕES E QUESTIONAMENTOS}

Um aspecto explicitado no desenvolvimento do processo grupal foi a dificuldade demonstrada pelos jovens em falarem sobre seu sofrimento psíquico ou de serem reconhecidos como usuários de serviços de saúde mental. Ressentiam-se dos 
rótulos e estigmas que thes eram impingidos, por serem usuários desses programas. Alguns, inclusive, desistiam de freqüentar a $A A G$ ou não participavam dos eventos externos para não serem identificados como portadores de transtornos mentais. Abordavam a vergonha de se expor, do medo das outras pessoas, "do que os outros iriam pensar", ou falavam simplesmente: "não é o que eu penso é o que a sociedade pensa", ou ainda o "pessoal da minha escola é muito sarrista".

Explicitavam que não queriam participar, pois não tinham nenhum problema mental ou falavam abertamente que não eram problemáticos ou loucos. Constatei que o estigma em relação à sua situação de saúde mental era mais problemático na vida desses jovens do que as dificuldades que tinham para lidar com as situações do cotidiano. É importante ressaltar que essas situações foram apresentadas espontaneamente durante o processo grupal, o que entendo estar relacionado com a dinâmica dos encontros, com o estabelecimento de vínculos de confiança entre os profissionais e os jovens que permitia, durante as atividades, uma troca de experiências. Embora estes encontros não fossem caracterizados como um trabalho clínico-terapêutico, se constituíam enquanto espaços para os sujeitos falarem de seu sofrimento psíquico e das dificuldades que tinham com esta questão. Em alguns momentos, verificouse partilha de emoções e relatos de situações de intenso sofrimento vividos pelos jovens.

Um dado observado nas falas dos jovens, que considerei bastante preocupante, referiu-se aos motivos que os levaram a serem atendidos na saúde mental. Dentre os motivos, constatei uma ênfase nas dificuldades de convívio na escola ou na família. Os jovens apresentavam situações que estavam mais relacionadas à ausência de diálogos, à falta de tolerância entre os sujeitos e a não compreensão das diferenças. Esses dados denunciavam as dificuldades das instituições, neste caso familiar-escolar, de trabalharem os conflitos e as dificuldades que surgem no cotidiano. Constatei, pela fala dos jovens, que uma prática bastante disseminada nestas instituições é a de recorrer aos saberes psiquiátricos e psicológicos para responder a uma demanda oriunda da complexidade e das contradições decorrentes do sistema social na qual se inserem. Situação ainda mais grave ocorre no âmbito escolar que freqüentemente transfere a responsabilidade para os sujeitos de problemas históricos e culturalmente construídos na sociedade. É bastante comum legitimar o fracasso do sistema escolar pelo aluno, culpabilizando-o por não se adequar ao sistema. E $\mathrm{S} S$ e $\mathrm{s}$ dados me levaram a questionar sobre a dificuldade das instituições sociais em conviverem com as diferenças, com a diversidade de comportamentos e de identidade, produzindo, cada vez mais, sofrimentos psíquicos. Penso também nos prejuízos que se colocam para a identidade dos jovens que, por não se conformarem às estruturas socialmente construídas, são rotulados e estigmatizados enquanto doentes mentais.

Tornou-se evidente então a necessidade de se considerar outros segmentos sociais onde esses jovens estavam inseridos, procurando refletir sobre a sua importância na vida desses sujeitos, bem como envolver as instituições em propostas voltadas para a questão da saúde mental.

Considero também necessário construir propostas que partam dos interesses e necessidades dos jovens. Em uma avaliação realizada, sugeriram a realização de atividades diferentes como sessões de filmes, palestras e debates envolvendo outros jovens, passeios em conjunto, idas ao cinema. Das atividades já realizadas, a informática foi uma das que suscitou maior interesse por parte dos jovens. Esta questão merece um olhar mais cuidadoso se considerarmos que a motivação e a vinculação dos sujeitos se dá principalmente pela satisfação de seus interesses e motivos. Considero também que a inserção em outros contextos sociais e a convivência com outros jovens pode contribuir para trabalhar os preconceitos e estigmas, reduzindose assim a exclusão social. Para isto é importante que não sejam práticas fechadas, voltadas apenas para os jovens que passam por serviços de saúde mental, mas que envolvam outros jovens da comunidade, buscando-se assim maior interação, troca e conhecimento.

Realizar esta pesquisa, abordando uma prática grupal com jovens no âmbito da saúde mental, foi um grande desafio, enquanto pesquisadora e profissional. Embora já tivesse, pela experiência profissional, trabalhado com outras práticas grupais, tinha pouco conhecimento sobre 
a questão da saúde mental. Este desconhecimento me levava a ter uma concepção de saúde mental muito próxima a do senso comum, onde transtorno mental é muitas vezes compreendido enquanto um estado de alienação ou incapacidade intelectual.

De certo modo, por conhecer alguns dos participantes, já vinha rompendo com esta concepção. Em virtude da pesquisa, procurei estudar alguns aspectos da reforma psiquiátrica, obtendo mais informações sobre a saúde mental, a inserção social do portador de sofrimento psíquico, que me ajudaram a romper com paradigmas que estavam presentes no meu conceito inicial. Desvelando este universo, revia meus próprios preconceitos em relação aos sujeitos pesquisados à medida que ampliava meu olhar sobre a realidade observada. Aos poucos ia percebendo o potencial e a capacidade criativa dos jovens que, apesar de todo estigma e exclusão social, foram se revelando durante os encontros como extremamente participativos durante as atividades. Percebi o quanto esses jovens possuem uma visão crítica da realidade, que os mesmos freqüentam outras atividades sociais, que têm interesses, sonhos e projetos de futuro e, acima de tudo, demonstram uma enorme gama de perseverança para se manterem ativos nesta sociedade marcada pelo preconceito e exclusão social.

Esta convivência foi muito gratificante por me permitir partilhar do universo afetivo dos participantes e observar a sensibilidade e a afetividade presentes em vários momentos dos encontros. Fez-me acreditar na importância da construção e do fortalecimento de espaços como esses, para que os jovens possam dialogar, reconhecerem-se enquanto sujeitos e interagir com outros iguais.

Poderia citar inúmeras transformações ocorridas nestes encontros, das modificações das relações afetivas, das vivências de apoio e solidariedade observadas dentro e fora do espaço institucional. Indicadores destas transformações eram sinalizadas quando os jovens abordavam modificações nas suas relações familiares, escolares e de trabalho e a inserção em outros espaços sociais. Havia relatos de melhoria na convivência familiar e de retorno à escola; depoimentos de jovens que começaram a trabalhar após participar dos encontros, outros relatavam suas expectativas em relação ao futuro, abordavam a escolha profissional, o preparo para o vestibular e a busca de projetos de vida.

Percebi que, conforme aumentava a compreensão dos participantes da sua presença nos encontros, aumentava também o nível de vinculação deles ao grupo.

Ao trabalhar com os processos grupais, não pude deixar de refletir sobre as relações afetivas que permearam este processo. Observei o quanto foi importante a afetividade nesta interação entre os jovens. Acredito que a afetividade possibilitou o crescimento e o fortalecimento desta relação grupal, ajudando também na constituição da identidade de cada um.

Penso que as práticas grupais que reconhecem e permitem a partilha das emoções e a vinculação entre os participantes por meio da expressão do afeto e da solidariedade, possibilitam a construção verdadeira de caminhos de cidadania para extinção da estigmatização e exclusão social.

As práticas grupais, enquanto um espaço de convivência e de troca, possibilitam trabalhar os conceitos e preconceitos que se têm em relação ao transtorno mental, rompendo com resistências e aproximando a sociedade das pessoas que tem sofrimento psíquico. Acredito que boa parte destes preconceitos são calcados no desconhecimento sobre a questão da saúde mental, que podem ser transformados conforme aumenta o conhecimento das pessoas em relação ao assunto.

A análise dos dados apontou para uma riqueza de informações que podem contribuir para reflexão e elaboração de estratégias e/ou experiências no enfrentamento ao modelo psiquiátrico tradicional. Contudo, defrontei-me com inúmeras questões que demandam maior aprofundamento, se não quisermos incorrer em equívocos de reproduzir nas novas práticas, velhas e autoritárias formas de trabalho social.

Estas reflexões sobre tema tão complexo, que tive a pretensão de apresentar neste trabalho, são apenas para analisar uma prática social de grupo desenvolvida com jovens no âmbito da saúde mental, trazendo algumas possibilidades para repensar esta prática e possibilitando a construção de novas formas de agir, de novos saberes voltados ao paradigma psicossocial 
apontado pela Reforma Psiquiátrica Brasileira.

ABSTRACT: In this work reflections are presented about a practice that was done with youngsters in Mental Health. It summarizes part of a research that was done for a master dissertation in Psychology. I used, as a theoretical reference, authors from the Social Psychology area, who work with a dialectic concept of men and group, mainly the studies of Ignácio Martín-Baró and Silvia Lane. Those authors advocate that the group is a process that is filled with contradictions, which reflect the society where their members are inserted. I also intended to reflect about that practice in the context of the transformations that are being done under the Psychiatric Reform. Regarding the methodological aspects, I made use of the qualitative research and, as a tool for data collection, of the participative observation. The empiric data was grouped and analyzed under the light of the theoretical categories signaled by the cited authors. The research results pointed to the importance of reflecting about the social practices that are conducted at different social contexts, trying to adapt them to the population's reality, besides the need of spaces of social interaction opened to the dialog and to the construction of affective connections, which are important for the strengthening of those youngsters identity. In the context of mental health, I also consider important to approach the interaction with other social segments, allowing the construction of an interdiscipline practice, which permit the multiplication of the information, working over the pre-concepts and therefore reducing the social exclusion.

KEYWORDS: Group Process; Adolescents; Social practice; Mental health.

\section{REFERÊNCIAS}

BARROS, R.D.B. et al. A desinstitucionalização da loucura, os estabelecimentos de cuidado e as práticas grupais. In: VILELA, A.M.J.; CEREZZO, A.C.; RODRIGUES, H.B.C.(Org.). Clyo-Psyché hoje: fazeres e dizeres psi na História do Brasil. Rio de Janeiro: FAPERJ, 2001.

HELLER, A. O cotidiano e a história. 6. ed. São
Paulo: Paz e Terra, 2000.

LANE, S.T.M. O processo grupal. In: LANE, S.T.M;. CODO M. (Org). Psicologia social: o homem em movimento. 12. ed., São Paulo: Brasiliense, 1984, p.79-98.

LANE, S.T.M; FREITAS, M.F.Q. Processo grupal na perspectiva de Martin-Baró: reflexões acerca de seis contextos concretos. Revista Interamericana de Psicologia. São Paulo, v. 31, n. 2, p.293-308, 1997.

MARTIN-BARÓ, I. Sistema,grupo y poder: psicologia social desde Centroamerica II. San Salvador : UCA, 1993.

MINAYO, M. C. S. O desafio do conhecimento. São Paulo: Hucitec, 2000.

RAMOS, F.R. S. et al. Bases para uma resignificação do trabalho de enfermagem junto ao adolescente, In:

(Org.) Adolescer: compreender, atuar, acolher. Projeto Acolher. Brasília: Associação Brasileira de Enfermagem, 2001.

SALLAS, A. L. F. et al. Os jovens de Curitiba: esperanças e desencantos, juventude, violência e cidadania. Brasília: UNESCO, 1999.

ENDEREÇO DA AUTORA: Rua Rodrigues Alves, 233/702 Curitiba/PR 80240-460

cgusmao@mps.com.br 